Hum Hered 2009;67:145-146

DOI: $\underline{10.1159 / 000179562}$

\section{Comments on: Review and Evaluation of Methods Correcting for Population Stratification with a Focus on Underlying Statistical Principles}

\author{
Prakash Gorroochurn a, Susan E. Hodge ${ }^{\text {a, b }}$, Gary A. Heiman c, \\ David A. Greenberg a, b \\ aDivision of Statistical Genetics, Department of Biostatistics, \\ Mailman School of Public Health, Columbia University, \\ ${ }^{b}$ Division of Epidemiology, New York State Psychiatric Institute, \\ New York, N.Y., 'Department of Genetics, Rutgers University, \\ Rutgers, N.J., USA
}

We read with great interest the article by Tiwari et al. [1] which provides an extensive review of several recent methods to correct for population stratification (PS) in both family-based and population-based association studies. An important aspect of the paper is that it also focuses on the key statistical principles (such as randomization, conditioning on sufficient statistics, etc.) that underlie many of the correction procedures.

Although the authors spend considerable time on TDT and TDT-based methods, and also on structured association and major developments of the latter, their treatment of genomic controlbased methods seems to be somewhat perfunctory. This is in spite of the fact that the latter, together with a more recent principal component-based method [2,3], appear to be the most widely used population-based methods to date. Genomic control-based methods are statistically more powerful than family-based methods, are relatively simple conceptually, and are less computationally intensive than structured association methods, particularly in a genome-wide setting. We therefore think it would be appropriate for the readers of Human Heredity to be cognizant of several key improvements in genomic control (GC) that have taken place recently. We summarize these below:

\section{Robust Genomic Control (RGC)}

The genomic control test statistic is often based on an additive genetic model and uses the Armitage trend test which also has 1 d.f. $[4,5]$. However, with many complex diseases, the mode of inheritance is unknown, i.e. there is no information as to whether the underlying genetic model is dominant, recessive, multiplicative, or additive. In such a case, the general chi-square test for association is based on a $2 \times 3$ table and has 2 d.f., so that the usual GC correction cannot be applied. Zheng et al. [6] thus proposed RGC, which effectively decomposes the original 2 d.f. chisquare into two 1 d.f. chi-squares. GC correction is then applied to each of these chi-squares, by dividing each by a suitable variance inflation factor obtained from the null markers.

\section{Weighted-Average Statistic (WA)}

The WA test [7] is similar in spirit to RGC in that it performs under different modes of inheritance of disease. WA is simply an appropriately weighted combination of the classical GC and HWD, the latter being a test for Hardy-Weinberg disequilibrium $[8,9]$. The principle behind WA is that, under either a recessive or additive model, HWD has more power than GC, but the reverse is true under a multiplicative model. WA thus tries to 'overcome the weaknesses, and to maintain the advantages, of each of these individual statistical tests' [7].

\section{F-Based Genomic Control (GCF)}

GCF was proposed by Devlin et al. [10] to counter possible anti-conservativeness of the classical genomic control method (GC), especially in situations when the test size $\alpha$ is extremely small (as in a genome-wide scan). The major difference between GCF and GC is that whereas the latter uses a critical value based on a $\chi_{1}^{2}$ distribution, the former uses a larger critical value, one based on an $F_{1, L}$ distribution, where $L$ is the number of neutral loci on which the correction is based. Devlin et al. [10] showed that GCF is superior to GC in terms of controlling the Type-I error rate, when the latter is very small.

\section{Delta-Centralization (DC)}

Tiwari et al. [1] point out that two of the major drawbacks of classical GC are: (a) if the non-centrality parameter associated with the chi-square test statistic used in GC is large, then GC will lose power; (b) GC uses a uniform correction factor for all test loci, although the latter might have different allele frequencies and thus need different correction factors. Both of these key drawbacks have been recently addressed by Gorroochurn et al. [11, 12], who show that DC performs well for all values of the non-centrality parameter and is locus specific. The locus specificity of DC is an important advantage because each test locus is usually affected by a different degree of population stratification, thus a different correction factor is needed for each one. DC operates under a matching strategy under which null loci are selected such that their allele frequencies closely match those of the test locus, in the controls. The gist of the DC method is that it centralizes the noncentral chi-square in a more accurate way, by directly estimating the non-centrality parameter, instead of dividing by an inflation factor, as GC does. Gorroochurn et al. [11, 12] have shown that DC outperforms GC, especially for large values of the non-centrality parameter (which corresponds to large amounts of PS). Robust improvements of DC were subsequently made by Yang et al. [13].

We have already moved into the era of genome-wide association studies. The task ahead is a truly daunting one. Tiwari et al.'s [1] timely review will help us appreciate what has already been achieved and also point to future directions. Statistical validity, computational burden, and conceptual simplicity will all be major players in determining the statistical apparatus we will use in

\section{KARGER}

Fax +41613061234 E-Mail karger@karger.ch www.karger.com
(C) 2008 S. Karger AG, Base 0001-5652/09/0672-0145\$26.0/0 
the future. Genomic control and its recent improvements still offer an attractive tool in our task ahead, and can be used in conjunction with other increasing popular methods $[2,3,14]$.

\section{References}

-1 Tiwari HK, Barnholtz-Sloan J, Wineinger N, Padilla MA, Vaughan LK, Allison DB: Review and evaluation of methods correcting for population stratification with a focus on underlying statistical principles. Hum Hered 2008;66:67-86.

-2 Patterson N, Price AL, Reich D: Population Structure and Eigenanalysis. PLoS Genet 2006;2:e190.

- 3 Price AL, Patterson NJ, Plenge RM, Weinblatt ME, Shadick NA, Reich D: Principal components analysis corrects for stratification in genomewide association studies. Nat Genet 2006;38:904-909.

4 Sasieni PD: From genotypes to genes: doubling the sample size. Biometrics 1997;53:1253-1261.

5 Guedj M, Nuel G, Prum B: A Note on allelic tests in case-control association studies. Ann Hum Genet 2008;72:407-409.

6 Zheng G, Freidlin B, Gastwirth JL: Robust genomic control for association studies. Am J Hum Genet 2006;78:350-356.

7 Song K, Elston RC: A powerful method of combining measures of association and Hardy-Weinberg disequilibrium for fine-mapping in case-control studies. Stat Med 2006;25:105-126.

-8 Feder JN, Gnirke A, Thomas W, Tsuchihashi Z, Ruddy DA, Basava A, Dormishian F, Domingo R Jr, Ellis MC, Fullan A, Hinton LM, Jones NL, Kimmel BE, Kronmal GS, Lauer P, Lee VK, Loeb DB, Mapa FA, McClelland E, Meyer NC, Mintier GA, Moeller N, Moore T, Morikang E, Prass CE, Quintana L, Starnes SM, Schatzman RC, Brunke KJ, Drayna DT, Risch NJ, Bacon BR, Wolff RK: A novel MHC class I-like gene is mutated in patients with hereditary haemochromatosis. Nat Genet 1996;13:399-408.
-9 Nielsen DM, Ehm MG, Weir BS: Detecting marker-disease association by testing for Hardy-Weinberg disequilibrium at a marker locus. Am J Hum Genet 1998;63:1531-1540.

10 Devlin B, Bacanu SA, Roeder K: Genomic control to the extreme. Nat Genet 2004;36:1129-1130.

- 11 Gorroochurn P, Heiman GA, Hodge SE, Greenberg DA: Centralizing the non-central chi-square: a new method to correct for population stratification in genetic case-control association studies. Genet Epidemiol 2006;30:277-289.

12 Gorroochurn P, Hodge SE, Heiman GA, Greenberg DA: A unified approach for quantifying, testing and correcting population stratification in case-control association studies. Hum Hered 2007;64:149-159.

13 Zang Y, Zhang H, Yang Y, Zheng G: Robust genomic control and robust delta centralization tests for case-control association studies. Hum Hered 2007;63:187-195.

14 The Wellcome Trust Case Control Consortium: Genome-wide association study of 14,000 cases of seven common diseases and 3,000 shared controls. Nature 2007;447:661-678.

Prakash Gorroochurn

Division of Statistical Genetics, R620

Department of Biostatistics, Columbia University

722 W 168th Street, New York, NY 10032 USA)

Tel. +1 212342 1263, Fax +1 2123420484

E-Mailpg2113@columbia.edu 